\title{
NUEVA CATEQUESIS, NUEVOS CATEQUISTAS
}

DOI: https://doi.org/10.52039/seminarios.v60i2010.223

FERNANDO SEBASTIÁN*

El Espíritu lleva ya muchos años queriendo promover en nuestra Iglesia un movimiento de renovación. Esta era la razón profunda del Concilio Vaticano II. Renovar espiritualmente la Iglesia de Dios y ponerla en condiciones de evangelizar el mundo actual. Es obvio que la renovación y el vigor misionero de la Iglesia dependen de la autenticidad de nuestra fe, de nuestra respuesta a la gracia y a los dones de Dios. La acción del Espíritu de Dios es siempre fuerte y abundante. Los sacramentos son fuentes inagotables de gracia y santidad. El poder santificador del Señor resucitado es universal y permanente. Somos nosotros, es nuestra respuesta la que limita y reduce la eficacia de la acción santificadora de Dios. Por eso, en última instancia, la renovación de la Iglesia, las llamadas a una nueva evangelización se reducen a mejorar la respuesta de fe de los cristianos, a ayudar a los miembros de la Iglesia a entregarse más a Dios y vivir más santamente. El resto es secundario e insuficiente si falta esta primera exigencia.

Está claro que el momento decisivo para la cualificación de la fe de los cristianos es el de su primera incorporación a la Iglesia. Siempre podemos mejorar. Toda la vida es tiempo de salvación. Pero es evidente que el nivel espiritual y misionero de la Iglesia está condicionado por el nivel de conversión y de vida espiritual que tienen los nuevos cristianos, jóvenes o adultos, que se van incorporando día a día a la comunidad cristiana. Si el proceso de iniciación se hace bien y los nuevos cristianos llegan a la comunidad cristiana con verdaderos deseos de vivir santamente según la voluntad de Dios, la comunidad cristiana será una comunidad fervorosa, testimoniante, capaz de atraer y convencer a otros a la fe de Jesucristo. Si el proceso de iniciación se hace superficialmente y los nuevos cristianos no viven un proceso de verdadera conversión de manera que las celebraciones sacramentales no suponen un verdadero cambio de vida y un crecimiento en la vida espiritual, la comunidad cristiana poco a poco se va vaciando de verdadera substancia religiosa y se convierte en una comunidad formal, empobrecida religiosamente y colonizada por la cultura y las formas de vida circundantes. Una comunidad así no es capaz de evangelizar ni de convencer a nadie.

* Fernando Sebastián Aguilar es arzobispo emérito de Pamplona y Tudela. Creado Cardenal por el papa Francisco el día 12 de enero de 2014. 
En todo esto lo decisivo, lo que a nosotros nos atañe y depende estrictamente de nosotros, es la calidad y los objetivos de nuestra catequesis. Aunque en otros tiempos las cosas hayan podido ser de otro modo, hoy, la catequesis, sobre todo la catequesis de los adolescentes y la preparación para el matrimonio, tiene que ser una catequesis de conversión, una catequesis práctica que ponga a los nuevos cristianos ante la necesidad de cambiar de vida, de arrepentirse de sus pecados y ajustarse a los mandamientos y ejemplos del Señor como modelo y fuente de vida integral y permanente. Así nos lo están presentando los Papas desde los tiempos de Pablo VI, en Evangelii Nuntiandi (EN) (1975) y Juan Pablo II, en Catechesi Tradendae (CT) (1979).

El título de este escrito puede parecer un poco agresivo. Alguien puede decir «demasiadas novedades». Pero tiene un fondo de verdad. Y expresa la urgencia de la situación. Todo puede quedar bien si lo pensamos con realismo y con un buen sentido de Iglesia. Cuando hablamos de «novedades», no se trata de menospreciar el pasado, sino de renovarnos constantemente en la continuidad, sin rupturas, para responder mejor a las necesidades de cada momento, y transmitir a las nuevas generaciones la fe católica de siempre en toda su plenitud y toda su hermosura, en toda su fuerza y su fecundidad.

Estamos en plena sintonía con la Iglesia, el Papa Francisco no cesa de invitarnos a recuperar la autenticidad y el realismo de la fe, la novedad de la vida cristiana en sus verdaderos perfiles evangélicos.

\section{NUEVA EVANGELIZACIÓN}

A estas horas ya todos sabemos las características de la Nueva Evangelización. Tratemos de exponer un breve resumen de lo que este concepto significa para nosotros. La llamada a una nueva evangelización es la respuesta de la Iglesia a una crisis generalizada de fe en nuestro mundo occidental, fuera y también dentro de la Iglesia.

-En nuestros países occidentales se ha quebrado la transmisión pacífica de la fe a las nuevas generaciones. Los jóvenes bautizados tienen especiales dificultades para llegar a vivir la fe bautismal personalmente.

-Las dificultades vienen, en parte, de las mismas familias. Antes los niños eran iniciados en la fe desde los primeros años a través de la convivencia familiar. Ahora este cauce de transmisión falla en muchos casos. Los padres conviven menos con los hijos. Muchas familias católicas tienen una vida religiosa deficiente, no asisten a la eucaristía dominical, no tienen costumbre de rezar en familia. En la convivencia familiar no aparece con suficiente nitidez el testimonio de la fe vivida, no hay contagio de fe.

-A esta debilidad educativa de la familia, hay que añadir la falta de ambiente religioso en muchos colegios. En casi todos los colegios públicos los niños encuentran un ambiente adverso, contrario a la fe y a la Iglesia. En muchos cole- 
gios concertados no encuentran tampoco la ayuda que necesitan para creer con firmeza a pesar del ambiente de incredulidad y de irreligiosidad en que viven.

-Porque, en tercer lugar -y este es el dato fundamental-, tenemos que tener en cuenta que los niños asimilan rápidamente lo que encuentran a su alrededor, y hoy a su alrededor tienen una cultura y unos ejemplos de vida que no les ayudan a iniciarse en la fe, a entrar en una relación personal con Dios, con Jesucristo, sino que más bien los introducen insensiblemente en una forma de vida sin referencias religiosas, centrada en las cosas de este mundo, en sus propios intereses personales, sin horizontes de transcendencia, ni referencias religiosas de ninguna clase.

En resumidas cuentas, nueva evangelización significa «Pastoral de la Fe». Es una pastoral que tiene como objetivo primero y directo la ayuda para creer, el surgimiento y el fortalecimiento de la fe.

Estos son los fines que el Papa Benedicto XVI asignó al «Año de la Fe». Estas son sus palabras: "Sucede con frecuencia que los cristianos se preocupan de las consecuencias sociales, culturales y políticas de su compromiso, al mismo tiempo que siguen considerando la fe como un presupuesto obvio de la vida común. De hecho, este presupuesto no sólo no aparece como tal, sino que incluso con frecuencia es negado. Mientras que en el pasado era posible reconocer un tejido cultural unitario, ampliamente aceptado en referencia al contenido de la fe, y a los valores inspirados por ella, hoy no parece que sea ya así en vastos sectores de la sociedad, a causa de una profunda crisis de fe que afecta a muchas personas» (PF 2).

Por lo cual, el Papa quiere que el Año de la Fe sea «una invitación a una auténtica y renovada conversión al Señor, Salvador del mundo» (PF 6), que nos haga «redescubrir la alegría de creer y volver a encontrar el entusiasmo de comunicar la fe» (PF 7). Porque «la fe sólo crece y se fortalece creyendo. No hay otra posibilidad para alcanzar la certeza sobre la propia vida que abandonarse, en un in crescendo continuo, en las manos de un amor que se experimenta siempre como más grande porque proviene de Dios» (PF 7).

El Papa, al proclamar el Año de la Fe, pretende promover en la Iglesia la «pastoral de la fe». Lo dice con estas palabras, «quisiera esbozar un camino para comprender mejor no sólo los contenidos de la fe, sino -juntamente con eso- el acto con el que decidimos entregarnos totalmente y con plena libertad a Dios» (PF 10).

Al enunciar su intención, hace una indicación muy importante, que nos viene muy bien en este momento de nuestra reflexión. La intención del Papa no es animarnos a conocer mejor «las cosas de la fe», sino a creer más profunda-mente en Dios. Porque, antes que el conocimiento de cosas y misterios, «la fe es decidirse a estar con el Señor para vivir con él» (PF 10). Nos viene bien recordar lo que el Papa decía, más o menos con estas palabras, en su Encíclica Deus 
caritas est: «No se comienza a ser cristiano aprendiendo por un proceso ético o por determinadas razones, sino mediante un encuentro personal con Jesucristo como salvador de la vida, en nombre de Dios por el Espíritu Santo». Comenzar a creer es aprender a «vivir con Jesús», a «estar con Jesús», a «obedecer y seguir a Jesús».

Sin necesidad de buscar más, en este precioso documento el Papa nos da los elementos que deben guiarnos en nuestra reflexión:

- estamos viviendo una crisis general de fe;

-esta crisis tiene unas causas generales de orden cultural;

-no basta atender a los contenidos de la fe, sino que hay que atender especialmente al acto "personal y comunitario» por el cual nos entregamos libre y totalmente a Dios.

De lo cual tenemos que sacar nosotros las siguientes consecuencias. Para hacer una catequesis adecuada a las necesidades de nuestro tiempo:

-necesitamos ver con claridad cuáles son las dificultades que tienen nuestros jóvenes para creer en Cristo, en Dios y en sus promesas de salvación;

-necesitamos conocer la cultura en la que viven y cuales son los elementos de esta cultura que les dificultan su decisión para creer.

-necesitamos renovar nuestra comprensión de la fe;

-necesitamos promover un estilo de catequesis que tienda especialmente a favorecer el despertar y el crecimiento de la fe en los catecúmenos.

Esta misma es la preocupación dominante de las predicaciones del Papa Francisco y de su Carta encíclica Lumen Fidei. La fe reconoce el amor de Dios manifestado en Jesús como el fundamento sobre el que se asienta la realidad y su destino último. Creemos en un Dios que interviene en la historia resucitando a los muertos. Nuestra cultura ha perdido la percepción de Dios. No pensamos que pueda intervenir de verdad en nuestra vida. Por eso nos parece que da igual creer o no creer. Vivir sin fe es vivir para morir, vivir muerto, sin futuro, sin esperanza, sin la alegría de la inmortalidad. La fe no sólo mira a Jesús, sino que mira desde el punto de vista de Jesús, con sus ojos: es una participación en su modo de ver. En muchos ámbitos de la vida confiamos en otras personas que conocen las cosas mejor que nosotros. Tenemos confianza en el arquitecto que nos construye la casa, en el farmacéutico que nos da la medicina para curarnos, en el abogado que nos defiende en el tribunal. Tenemos necesidad también de alguien que sea fiable y experto en las cosas de Dios. Jesús, su Hijo, se presenta como aquel que nos explica a Dios (cf. Jn 1,18). San Juan, creer a Jesús, creer en Jesús, creer con Jesús. La nueva lógica de la fe está centrada en Cristo. La fe en Cristo nos salva porque en él la vida se abre radicalmente a un Amor que nos precede y nos transforma desde dentro, que obra en nosotros y con nosotros. En la celebración de los sacramentos, la Iglesia transmite su memoria, en particular mediante la profesión de fe. Ésta no consiste sólo en asentir a un conjunto de verdades abs- 
tractas. Antes bien, en la confesión de fe toda la vida se pone en camino hacia la comunión plena con el Dios vivo. Podemos decir que en el Credo el creyente es invitado a entrar en el misterio que profesa y a dejarse transformar por lo que profesa. Asimilada y profundizada en la familia, la fe ilumina todas las relaciones sociales. Como experiencia de la paternidad y de la misericordia de Dios, se expande en un camino fraterno. En la «modernidad» se ha intentado construir la fraternidad universal entre los hombres fundándose sobre la igualdad. Poco a poco, sin embargo, hemos comprendido que esta fraternidad, sin referencia a un Padre común como fundamento último, no logra subsistir. Es necesario volver a la verdadera raíz de la fraternidad. Desde su mismo origen, la historia de la fe es una historia de fraternidad, si bien no exenta de conflictos. Dios llama a Abrahán a salir de su tierra y le promete hacer de él una sola gran nación, un gran pueblo, sobre el que desciende la bendición de Dios (cf. Gn 12,1-3). ¡Cuántos beneficios ha aportado la mirada de la fe a la ciudad de los hombres para contribuir a su vida común! Gracias a la fe, hemos descubierto la dignidad única de cada persona, que no era tan evidente en el mundo antiguo. En el siglo II, el pagano Celso reprochaba a los cristianos lo que le parecía una ilusión y un engaño: pensar que Dios hubiera creado el mundo para el hombre, poniéndolo en la cima de todo el cosmos. Se preguntaba: «¿Por qué pretender que [la hierba] crezca para los hombres, y no mejor para los animales salvajes e irracionales?» (46). "Si miramos la tierra desde el cielo, ¿qué diferencia hay entre nuestras ocupaciones y lo que hacen las hormigas y las abejas?» (47). En el centro de la fe bíblica está el amor de Dios, su solicitud concreta por cada persona, su designio de salvación que abraza a la humanidad entera y a toda la creación, y que alcanza su cúspide en la encarnación, muerte y resurrección de Jesucristo.

\section{CARACTERÍSTICAS DE UNA CATEQUESIS EVANGELIZADORA}

Ya sé que la idea estricta de catequesis supone la fe de los catequizandos. Algún purista podría decir que la catequesis no puede ser evangelizadora. La evangelización es previa a la catequesis. Pero en la pastoral, por exigencias de la caridad, hay que ser muy realistas. Si a nuestras catequesis vienen niños y jóvenes que no están claros ni firmes en la fe, no tenemos más remedio que pensar en una catequesis evangelizadora, ordenada al fortalecimiento y a veces al surgimiento de la fe. Lo mismo se puede decir de la catequesis de adultos.

En la catequesis acompañamos a los neófitos para que vayan descubriendo las riquezas de su fe, dando por supuesto que quienes acuden a la catequesis, sea antes o después del bautismo, tienen ya, aunque sea imperfectamente, la fe verdadera.

Esto es precisamente lo que dice el Papa Benedicto, que hoy no podemos dar por supuesto. No podemos dar por supuesto que los niños o los jóvenes o los adultos que vienen a la catequesis tienen fe. 
Con frecuencia no la tienen,

-porque no les han enseñado en su familia a creer, a vivir creyendo, en relación de adoración con Dios y con su enviado Jesucristo;

-o porque, aunque les hayan enseñado en casa a creer y a rezar, viven en un ambiente cultural que asfixia su fe.

En el caso concreto de nuestros jóvenes, de los adultos jóvenes con los que tratamos, llevan dentro la influencia de la cultura irreligiosa de nuestro mundo, que les empuja insensiblemente a vivir como si Dios no existiera. Si la conservan, su fe es vacilante, llena de dudas, difícilmente concorde con la fe de la Iglesia en muchos puntos de la doctrina y de la moral, incapaz de clarificar, organizar y dirigir su vida. No tienen la fe que necesitan para vivir cristianamente en el mundo actual. No tienen esa fe de la que habla el Papa «que transforma el corazón» y «dura tanto como el camino de la vida» (LF 1).

Antes de abordar la última parte de nuestra reflexión, necesitamos detenernos brevemente en dos cuestiones a las que hemos aludido anteriormente: la influencia de la cultura dominante, y la nueva teología de la fe.

1. Influencia de la cultura dominante. Para entender lo que queremos decir conviene aclarar qué entendemos aquí por cultura. Siguiendo las indicaciones del Concilio Vaticano II en Gaudium et Spes. Por cultura entendemos «la imagen de sí mismo y del mundo que uno lleva dentro de sí y con la que se rige en sus relaciones sociales y en sus acciones personales».

A estas horas sabemos que la fe, dentro del espíritu de cada creyente, tiene una estrecha relación con la cultura que vive y en la que vive. La fe se hace cultura, la fe influye en la cultura, y la cultura que uno lleva dentro influye también en facilitar o dificultar la fe personal, en sus aspectos más íntimos de decisión personal y en sus manifestaciones externas y comunitarias.

En virtud de la unidad interior de cada sujeto, lo que sabemos de una forma u otra, y lo que creemos, tiene que tener una armonía, una concordancia interior, que nos permita vivir y actuar con coherencia interior. No puede haber contradicción entre mi manera de entender el origen del mundo y mi fe en Dios creador, la sexualidad humana y la doctrina moral de la Iglesia, mi idea de libertad y la providencia de Dios, la mortalidad o inmortalidad del hombre y la vida eterna, por poner algunos ejemplos.

Hoy, la cultura dominante de occidente, la que los niños y jóvenes reciben en colegios, en los medios, en sus ambientes, es una cultura muy individualista, centrada en el bienestar inmediato, por tanto oportunista, relativista, poco realista, soñadora, sentimental, insegura, cambiante, con pocas o con ninguna referencia trascendente, ni religiosa, ni casi moral. Estamos aquí, no sabemos por qué, disfruta lo que puedas, ve con cuidado, no te fíes mucho de nadie, trata de pasarlo lo mejor que puedas. Ese es el mensaje que reciben en muchos colegios, y el mensaje que respiran en la sociedad en que viven. Estamos 
profundamente encerrados en el amor de nosotros mismos, por eso vivimos sin horizontes de trascendencia. Sólo así se explica la reacción terrorífica contra el intento de reducir algo la práctica del aborto en nuestra sociedad. Nadie piensa en la vida o los derechos del hijo. La izquierda defiende cínicamente el derecho de la mujer a decidir sobre su propio cuerpo, sobre su maternidad. No quieren admitir que el hijo no es parte del cuerpo de la madre sino que es otro ser, otra persona, en los primeros pasos de su existencia. Derecho a abortar es simplemente derecho a matar. Parece imposible, pero nuestra juventud asimila esta manera de pensar antes de lo que los adultos pensamos.

2. La nueva teología de la fe. En general, el estudio de la fe ha sido bastante deficiente en la Teología Católica. Lo era ya en la Escolástica y lo fue más aún tras la Reforma protestante. No hemos desarrollado la idea bíblica de fe, ni siquiera la doctrina sobre la fe y la justificación. Más bien hemos privilegiado la idea de fe como la aceptación de las cosas reveladas por Dios como verdaderas, y hemos dejado en la sombra el acto previo de fe en Dios (fe en Cristo y fe en Dios) en virtud del cual creemos lo que Cristo y el propio Dios nos han revelado. Al entender la fe como conocimiento, la hemos dejado a merced de los ataques racionalistas. La fe es siempre un conocimiento imperfecto, no evidente, en inferioridad de condiciones respecto de los conocimientos científicos. La verdadera respuesta está en mostrar la fe como relación de confianza con otro, movida por el amor. Como consecuencia de esta fe que damos a alguien creíble, podemos alcanzar conocimientos, no evidentes, pero sí seguros, firmes, fiables. Esto significa que tenemos que recuperar el esquema bíblico de la fe, con el modelo no de «creo algo», sino de "creo en Ti», «me confío y me entrego a Ti», por lo que creo lo que Tú me dices. Creo «algo» porque antes he creído en quien me lo dice.

Si tenemos en cuenta esta situación, resulta que en estos momentos necesitamos una catequesis:

a) Que ayude a creer en Dios y en Jesucristo con fe viva y operante; no se trata tanto de que aprendan el catecismo, las afirmaciones de la fe, cuanto de que den el paso personal de creer en Jesucristo y en Dios, de querer seriamente ajustar su vida a la propuesta y los dones de Dios en Jesucristo. Entendiendo la fe como adoración, como confianza, amor, obediencia, seguimiento. Si esta conexión de confianza y adoración existe, aceptar la verdad de las afirmaciones de fe ya no cuesta trabajo. Lo difícil es ayudarles a dar este paso decisivo de vivir con Jesús, aceptar a Jesús como norma suprema de la propia vida, en su relación con Dios, a los hermanos, con las cosas de este mundo, en sus proyectos de vida.

b) Que se preocupe de favorecer y fortalecer no sólo los contenidos de la fe, sino previamente la acción de creer en Dios, de poner la vida en sus manos, mediante la fe en su enviado Jesucristo; es preciso tener en cuenta estos dos niveles indispensables, creer en Jesús, creer en Dios; con sus consecuencias esenciales, prioridad de la vida eterna, amor gratuito y universal. 
c) Necesitamos lo que podríamos llamar una catequesis de conversión: a Cristo, a Dios, a la vida eterna, a la caridad, a la Iglesia. Con sus consecuencias reales, con un cambio real de vida, en los amigos, en los ambientes que se frecuentan, en el tiempo de ocio, en los ideales, valores, dinero, amor, etc. Una fe que transforma realmente la vida porque la somete eficazmente a la imitación de Jesús, y al reconocimiento de la voluntad de Dios manifestada en las enseñanzas y en la vida de Cristo. La fe es conversión en sentido fuerte.

d) Todo esto sin que podamos contar con la ayuda de la familia; ni siquiera con el interés verdadero del catecúmeno. Es preciso despertar su interés. Que vean que lo que están haciendo es «importante para su vida». Acostumbrados a hacer solo lo que les divierte.

e) En contra de los modelos de vida inmanentista y relativista, totalmente centrada en sí mismos, que nuestros jóvenes ven por todas partes; una catequesis que prepare a nuestros catecúmenos para vivir cristianamente en un ambiente hostil, inhóspito, agresivo.

Esto requiere llegar a lo profundo de la persona, influir en las decisiones más íntimas que configuran su mentalidad y rigen su vida; es decir requiere llegar a ese acto personal de fe en Dios por el cual el creyente decide la calidad de su vida. Esto requiere un clima de confianza, de credibilidad; un testimonio fuerte de vida práctica de fe; una clarificación de las ideas y sentimientos, una comunicación de mucha confianza y mucha sinceridad. Sin esto no puede haber educación, y mucho menos esta educación en la fe personal que tiene que ser la catequesis.

Si queremos describir los rasgos de esta catequesis, pienso que podemos señalar los siguientes:

a) Una catequesis que desde muy pronto despierte la fe. No se puede empezar la catequesis a los siete años, ni a los cinco. Esta catequesis inicial tendría que ser una catequesis familiar, convivencial, testimonial, práctica. Iniciar en la oración, en el amor, en la obediencia a Dios, a Jesús, a la Virgen María... iniciar en la vida virtuosa, desarrollar y afinar la conciencia moral.

Pero ¿qué hacer cuando esta iniciación primaria a la vida cristiana no se da en las familias? ¿Qué hacer cuando nos vienen niños de siete u ocho años que no saben rezar?

No podemos comenzar directamente a enseñar los contenidos de la fe como si ya fueran verdaderos creyentes. Hay que atender expresamente a suscitar la fe personal, a la vez que les enseñamos los principales contenidos, pero con cierta prioridad.

b) Una catequesis muy práctica. Hay que hablarles de Jesús y de Dios. Pero sobre todo hay que enseñarles prácticamente a tratar con ellos, a vivir con ellos, a contar con ellos en todos los momentos de la vida. El catequista tiene que rezar con ellos, adorar, practicar las virtudes cristianos con ellos, ayudarles a entrar 
en la experiencia real de la vida cristiana integral. ¿Qué hacen las madres para enseñar a hablar o a caminar a sus hijos? No les dan clases teóricas, sino que hablan y caminan con ellos. Así es como se enseña a creer, creyendo con ellos, viviendo la fe con ellos en todos los momentos y situaciones de la vida diaria.

Es fundamental tratar de incorporar a la familia, a las madres especialmente, a los padres, a los abuelos, a los hermanos mayores. ¿No hemos pensado en la catequesis familiar? Lo mejor sería que los padres aprendiesen a ser los catequistas, los iniciadores de sus hijos. Por lo menos en los primeros años. Tendríamos que convocar a los padres de los niños bautizados al año, cada año, y guiarles en la educación religiosa de sus hijos.

Con los adolescentes, con los jóvenes, hay que repetir el proceso. Cuando vienen a nosotros, tienen ya en la cabeza muchas objeciones, muchas reservas, aunque no las digan. Unas dificultades son teóricas: existencia o no existencia de Dios, creación o evolución, prejuicios contra la Iglesia, los sacerdotes. Otras muchas, y quizá más influyentes, son de tipo práctico, en relación con la vida moral, la sexualidad, el matrimonio, castidad y virginidad, control de la natalidad, aborto, cuestiones de bioética, fecundación artificial.

Viven en un mundo confuso, alborotado, rebelde. En los temas religiosos están acostumbrados a aguantar el chaparrón, sin poner en ello verdadero interés, cumplir el expediente, y luego seguir como si nada hubiera ocurrido. Hay que romper a toda costa esa defensa del desinterés. Necesitan muchas horas de escucha, de aclaraciones, de volver a fundamentar la fe inicial. Alguien podrá decir que esto es más que catequesis. No vale la pena discutir de palabras. Es la atención que nuestros jóvenes necesitan. Si no se la damos, lo demás no sirve de nada.

c) Dar a nuestras catequesis la fuerza y la intensidad de un verdadero catecumenado, un itinerario práctico de fe y de incorporación progresiva a la práctica de la vida cristiana en su conjunto.

El bautismo requiere, antes o después, pero indispensablemente, un catecumenado. Las circunstancias pastorales nos obligan a reconocer esta verdad tan elemental. Hoy no puede haber cristianos sin que pasen por un proceso catecumenal, entendido como un proceso de conversión personal a Dios y a su Reino, de entrega personal a Jesucristo y a la Iglesia, a la vida santa de la oración y de la caridad.

De esto se siguen muchas consecuencias prácticas. Vistas las cosas así, es evidente que la verdadera catequesis no puede limitarse a una hora escasa por semana. Hay que buscar la manera de aumentar este tiempo de «formación cristiana teórica y práctica». ¿Cómo se puede hacer? Tenemos que pensar en incorporar a este proceso de iniciación en la fe, a la labor catequética ordinaria, algunas jornadas de catequesis intensiva de conversión, algo parecido a los Cursillos de Cristiandad, Ejercicios Espirituales de dos o tres días, una peregrinación, un campamento, una visita a un monasterio, etc. 
d) Tiene que ser muy personal, muy de relación personal con cada catecúmeno, con su familia, muy en relación con su vida real, con sus ambientes.

Tiene que ser una catequesis muy práctica, muy experimental, muy realista, muy concreta, de rezar con ellos, de proponerles actos concretos de revisión, de corrección, de práctica de las virtudes, que luego se comentan con ellos, etc.

$Y$ a la vez tiene que ser muy comunitaria, es preciso que entren los chicos en el misterio de la celebración litúrgica. No con las canciones, por lo menos, no principalmente con las canciones ni con las guitarras, sino con la oración, con una verdadera asimilación de la oración litúrgica, de los sentimientos de la liturgia, fe, confianza, arrepentimiento, deseos, alabanza. No puede estar reñida la hondura litúrgica con la atención juvenil.

La catequesis parroquial tiene que relacionarse estrechamente con la labor del colegio, de la clase de religión, de la familia. Habría que llegar a elaborar un proceso unitario de formación que tenga en cuenta la colaboración de la familia, la parroquia, el colegio o las clases de religión. Bajo una misma dirección que corresponde al párroco y a sus colaboradores más cercanos.

Esta labor no se puede dejar en manos de nadie. El proceso de iniciación en la fe y en la vida cristiana tiene que estar personalmente dirigido en cada caso por el pastor. Hay que hablar con cada uno, con los padres, conocer los amigos, saber cómo reacciona por dentro el catecúmeno. Lo hace diariamente el catequista, pero tiene que hacerlo de vez en cuando el sacerdote responsable. Es el proceso de formación de los nuevos cristianos. Los sacerdotes no podemos estar ausentes.

En una pastoral de Nueva Evangelización hay que pensar en los adultos que llegan o vuelven a la Iglesia. Es indispensable pensar en un catecumenado de adultos. Si hay evangelización, tiene que haber nuevos cristianos, si hay nuevos cristianos tiene que haber catecumenado para adultos. Con todas las consecuencias.

Para lograr una catequesis evangelizadora tenemos que tener en cuenta lo que el Papa nos recomienda como características de la pastoral durante el «Año de la Fe», en su Carta de promulgación Porta fidei.

El Papa insiste fuertemente en esta idea de que el Año de la Fe sea realmente un año dedicado a la pastoral de la fe, un año de "evangelización», que es lo mismo que decir un año de "conversión». El Año de la Fe es «una invitación a una auténtica y renovada conversión al Señor, único Salvador del mundo».

En este planteamiento, el Papa no se conforma con una fe cualquiera; quiere que los cristianos vivan una fe auténtica, una fe verdadera. Esa fe que transforma la vida de los creyentes. La fe, que «actúa por el amor se convierte en un nuevo criterio de pensamiento y de acción que cambia toda la vida del hombre» (Rom 12,2; Col 3, 9-10; Ef 4, 20-29; 2C 5, 17). Cuando uno cree de verdad en Dios, y se pone en sus manos, guiado por la fe en Jesucristo, según la medida 
de nuestra disponibilidad, la mentalidad, los pensamientos, los sentimientos, las acciones del hombre se purifican y se transforman en un proceso que no termina en toda la vida.

Durante el Año de la Fe, es preciso que pongamos la fe en Cristo y la fe en Dios en el centro de nuestros objetivos pastorales. El Papa quiere que revisemos lo que estamos haciendo en la pastoral ordinaria en función de sus resultados de fe. La Iniciación Cristiana, tal como la hacemos actualmente, la catequesis, las eucaristías dominicales, ¿promueven esta fe firme, segura, transformante y misionera entre nuestros cristianos?

Aplicando estos criterios y como resumen de todo lo dicho hasta ahora, podemos decir que la catequesis en tiempos de evangelización tiene que ser una catequesis que despierte y desarrollo en los catecúmenos la fe verdadera, la fe que nos une espiritualmente a Cristo y a Dios, la fe que nos cambia la vida, por el amor a Dios, la esperanza de la vida eterna, y el amor verdadero y efectivo a los hermanos.

\section{Catequistas para los tiempos de eVAngelización}

El catequista es el principal agente de la catequesis. Por eso es también factor central de cuanto estamos diciendo. La catequesis no la hacen los libros, ni los materiales. La catequesis la hacen los catequistas. Hemos hecho muchos libros, muchos materiales. No sé si hemos cuidado suficientemente la preparación de los catequistas. Una preparación que hay que hacerla en cada diócesis, en cada parroquia. Con paciencia y con visión de futuro. Unas cuantas consideraciones prácticas.

a) Tenemos que ponderar mucho la importancia de los catequistas. Ponemos en su mano la tarea más importante de la Iglesia, la transmisión de la fe, la educación en la fe de los nuevos cristianos, sean niños, jóvenes o adultos. A estas horas el oficio de catequista tendría que ser un ministerio laical, oficialmente concedido por la Iglesia de manera pública y estable. Es una pena que no lo hayamos conseguido. Tenemos que proceder como si lo fuese. En realidad los catequistas cumplen un ministerio, una labor pública y ordenada al bien común de la comunidad eclesial.

b) En consecuencia, los catequistas tienen que ser testigos de la fe, capaces de enseñar a creer en Dios con las obras, con la vida, rezando con sus catecúmenos, acompañándolos personalmente en el surgimiento y en la maduración de su fe, en su conversión personal a Cristo y a Dios, en la renovación de su vida a medida que entran en el conocimiento y en la convivencia con Jesús, en el conocimiento de su vida y de sus enseñanzas, en su descubrimiento de Dios y en experiencia de la fe, en la práctica de las virtudes teologales y morales, etc. Acompañándoles en la práctica de la vida cristiana en general. Son verdaderos 
tutores de la fe de sus catecúmenos, pedagogos. Recordemos las palabras de san Pablo: «Os quiero como a hijos. Ahora que estáis en Cristo tendréis muchos tutores, pero padres solo tenéis uno. Yo os engendré para Cristo por medio del evangelio. Así pues os ruego que seáis imitadores míos (como yo lo soy de Cristo) (1 Cor 11, 1)». En otros lugares les dice a los cristianos que sean imitadores suyos, como él es imitador de Cristo (cf. Flp 3, 17).

c) El catequista tiene que ser cristiano de oración, cristiano de acción, entusiasta, dinámico, capaz de ilusionar con una nueva forma de vivir. Y capaz de dar confianza, de animarle y sostenerle en el conflicto consigo mismo, con su vida, con sus ambientes. El testimonio y la relación con el catequista tiene que ser más apreciable para el catecúmeno que todas las demás influencias que recibe en casa, en el colegio, en el ambiente general de la calle y de la conciencia. El catequista, con su cura, tienen que ser verdaderos referentes de vida para el niño, para el adolescente que está aprendiendo a ser cristiano.

d) Y tiene que tener una buena formación intelectual. Ser capaz de comprender el ambiente familiar y las reacciones del niño, su ritmo de desarrollo, su manera de percibir las cosas. En el caso de los adolescentes hace falta comprender y saber responder a las muchas dificultades teóricas y prácticas que llevan en la cabeza. Y poner las bases de una antropología cristiana elemental, sin la cual no puede mantenerse la fe: existencia de Dios, creación (en diálogo con lo que van descubriendo y afirmando hoy las ciencias), concepto verdadero de libertad, espiritualidad e inmortalidad; amor, sexualidad. No es una tarea fácil que se pueda improvisar.

e) De manera especial necesita una buena formación teológica en los temas fundamentales, una buena presentación de Jesucristo, Hijo de Dios hecho hombre; cómo presentar hoy la enseñanza de Jesús sobre Dios, la Trinidad, su providencia, sus relaciones con nosotros; una nueva y buena teología de la fe, ya no vale eso de «creer lo que no se ve». La fe como acción de poner nuestra vida en manos del Dios de Jesús, que nos ama, que nos resucita, amándole, orando, obedeciendo, viviendo como hijos suyos en el mundo. Hay que saber presentar la vida moral como consecuencia del seguimiento y del amor de Cristo, consecuencia del deseo y de la esperanza de la vida eterna. Hablar y actuar siempre y en todo en la perspectiva positiva y atrayente de la salvación, de la vida, del éxito de la existencia, como don de Dios. Con mucho amor, con mucha gratitud, con mucha humildad.

f) Los mejores catequistas no suplen la presencia del párroco o del sacerdote responsable. Catequizar es preparar para celebrar los sacramentos con fe viva y vivir la vida real de cada día según la voluntad de Dios que se nos manifiesta en Jesucristo por medio de su Iglesia. Una labor que admite toda la colaboración de los seglares, pero que es también sacerdotal. El sacerdote tiene que ser modelo, maestro, ayuda de los catequistas. 
g) El catecúmeno tiene que crecer a la vez en todos los aspectos de la fe, el catequista tiene que sentirse responsable y guía de la vida cristiana de sus catecúmenos, respaldado en todo ello por el Párroco. Dichos aspectos son:

-la oración personal y comunitaria;

- la vida litúrgica, eucaristía, sacramento del perdón;

-aprender a reconocer sus fallos, a examinarse, arrepentirse, renovarse, confesarse;

-virtudes teologales y morales;

- una buena presentación de la moral cristiana, persona, familia, vida social;

-ejercicio de la caridad, limosna, enfermos, acciones buenas positivas;

-sin miedos ni ambigüedades, en los diferentes ambientes donde vive. Poco a poco el catecúmeno tiene que irse diferenciando de los que no lo son. La conversión requiere rectificaciones, rupturas, formas nuevas de vida, renovación de valores, que reclaman otras formas de ocupar el tiempo, etc. Si la catequesis no cambia la vida del catecúmeno quiere decir que no le influye realmente;

-para que este crecimiento sea posible en un medio adverso, tiene que sentirse integrado en un grupo de compañeros y de adultos, en el que se sienta acogido, entendido, apoyado, normalizado;

-los catecúmenos no pueden sentirse solos, abandonados en el mundo, sino que tienen que sentir la realidad eclesial en la que viven, en la que crecen, la comunidad tiene que ser percibida como el mundo verdadero, un mundo real y amable, el mundo del corazón, del que salen y al que vuelven, en el que se sienten a gusto y encuentran su propia identidad. Como los astronautas en la nave, salen y entran, salen pero vuelven, están siempre conectados, se llevan consigo el mundo, el oxígeno del alma;

-hay que buscar, pues, el modo de que el joven cristiano se sienta más miembro de la comunidad eclesial que de la sociedad secular y descreída. Familia, parroquia, colegio y ocio han de ofrecerle ese contexto convivencial que necesita.

No es fácil alcanzar la mentalidad de evangelizadores. Vivimos en un continente de incredulidad. Tenemos que trabajar ante todo para promover la fe de nuestros oyentes, no la fe de saber muchas cosas, sino la fe de aceptar cordialmente a Jesucristo como Señor y Salvador, la fe de confiar en Dios y poner en Él el centro de nuestra vida y de nuestros deseos, la fe de no ser hijos del mundo, sino hijos de Dios, herederos de su gloria y ciudadanos del cielo, en contraste con un mundo que olvida a Dios y adora los bienes terrenales.

En una pastoral de evangelización nada en la Iglesia se puede organizar sin tener en cuenta a los que viven fuera del "campamento», a los que buscan, a los que se fueron o a los que todavía no han venido.

«En nuestro contexto cultural, muchas personas, aun no reconociendo en ellos el don de la fe, buscan con sinceridad el sentido último y la verdad de su existencia y del mundo. Esta búsqueda es un auténtico preámbulo de la fe» (PF 10). 
No podemos resignarnos a vivir en una Iglesia en permanente retirada. Hay que cambiar la tendencia. Tenemos que salir al encuentro de los que no creen con plena confianza en el poder convincente y salvador del Evangelio.

El Papa Francisco nos está invitando continuamente a salir de nuestros refugios, a acercarnos a los que no creen, a tratar sinceramente y amablemente con los que están lejos, para poder mostrarles con amor y sencillez las maravillas del amor de Dios y de los dones de Cristo. Tenemos que inventar medios de contacto con ellos, convocatorias para ellos, vínculos con ellos, que nos permitan llegar algún día a abrirles los tesoros de nuestra fe. Hemos de ser capaces de inventar fases diferentes, sostenerlos hasta la adultez, hasta el matrimonio, necesitamos tiempo para completar la formación moral, como consecuencia de la fe, del seguimiento, del deseo de salvación.

Este es el hermoso apasionante panorama que ponen ante nosotros estos tiempos de evangelización. Que María, la primera maestra y hasta catequista de Jesús, nos dé una generación entusiasta de catequistas sabios y santos, capaces de engendrar muchos nuevos cristianos, convertidos y convencidos. 